OPEN ACCESS

Edited by:

Stefano L. Sensi,

Università degli Studi G. d'Annunzio

Chieti e Pescara, Italy

Reviewed by:

Agata Copani,

Università degli Studi di Catania, Italy

Annamaria Cimini,

University of L'Aquila, Italy

*Correspondence:

A. Claudio Cuello

claudio.cuello@mcgill.ca

Specialty section: This article was submitted to

Neurodegeneration,

a section of the journal

Frontiers in Neuroscience

Received: 05 December 2018

Accepted: 21 January 2019

Published: 12 February 2019

Citation:

Cuello $A C$, Pentz $R$ and Hall $H$ (2019) The Brain NGF Metabolic

Pathway in Health and in Alzheimer's

Pathology. Front. Neurosci. 13:62.

doi: 10.3389/fnins.2019.00062

\section{The Brain NGF Metabolic Pathway in Health and in Alzheimer's Pathology}

\section{A. Claudio Cuello ${ }^{1,2,3 *}$, Rowan Pentz ${ }^{2}$ and Hélène Hall ${ }^{1}$}

${ }^{1}$ Department of Pharmacology and Therapeutics, McGill University, Montreal, QC, Canada, ${ }^{2}$ Department of Neurology and Neurosurgery, McGill University, Montreal, QC, Canada, ${ }^{3}$ Department of Anatomy and Cell Biology, McGill University, Montreal, QC, Canada

Emerging research has re-emphasized the role of the cortical cholinergic system in the symptomology and progression of Alzheimer's disease (AD). Basal forebrain (BF) cholinergic nuclei depend on target-derived NGF for survival during development and for the maintenance of a classical cholinergic phenotype during adulthood. In AD, BF cholinergic neurons lose their cholinergic phenotype and function, suggesting an impairment in NGF-mediated trophic support. We propose that alterations to the enzymatic pathway that controls the maturation of proNGF to mature NGF and the latter's ulterior degradation underlie this pathological process. Indeed, the NGF metabolic pathway has been demonstrated to be impaired in $A D$ and other amyloid pathologies, and pharmacological manipulation of NGF metabolism has consequences in vivo for both levels of proNGF/NGF and the phenotype of BF cholinergic neurons. The NGF pathway may also have potential as a biomarker of cognitive decline in $A D$, as its changes can predict future cognitive decline in patients with Down syndrome as they develop preclinical Alzheimer's pathology. New evidence suggests that the cholinergic system, and by extension NGF, may have a greater role in the progression of $A D$ than previously realized, as changes to the $\mathrm{BF}$ precede and predict changes to the entorhinal cortex, as anticholinergic drugs increase odds of developing $A D$, and as the use of donepezil can reduce rates of hippocampal and cortical thinning. These findings suggest that new, more sophisticated cholinergic therapies should be capable of preserving the basal forebrain thus having profound positive effects as treatments for AD.

Keywords: nerve growth factor, cholinergic system, Alzheimer's disease, basal forebrain cholinergic nuclei, trophic support

\section{INTRODUCTION}

The extraordinary discovery of nerve growth factor (NGF) by Rita Levi Montalcini and Stan Cohen, under the umbrella of Victor Hamburger's laboratory (Cohen et al., 1954; Newmark, 1986; Cowan, 2001), not only brought a Nobel Prize to Rita Levi-Montalcini and Stan Cohen but also opened the way to the discovery of many other trophic factors and their receptors. This family plays a very significant role in the development and function of peripheral and central nervous system (CNS) neurons, and critically, some trophic mechanisms appear altered in neurodegenerative conditions. This brief review focuses on the significance of NGF for the maintenance of the cholinergic 
phenotype in the mature and fully differentiated CNS. It discusses the existence of a metabolic pathway explaining the release of the NGF precursor molecule and its maturation and degradation in the extracellular space. Furthermore, we discuss the compromise of this pathway in Alzheimer's disease (AD), explaining the well-established atrophy of NGF-dependent cholinergic neurons of the basal forebrain (BF), and the possibility of deriving accessible biomarkers of $\mathrm{AD}$ in preclinical stages based on the NGF metabolic deregulation. Lastly, we discuss possible therapeutic interventions to normalize the NGF metabolism in $\mathrm{AD}$, thus protecting the viability of the cortical and hippocampal "cholinergic tone."

\section{NGF IS RESPONSIBLE FOR THE MAINTENANCE OF THE CHOLINERGIC PHENOTYPE}

Nerve growth factor has been clearly implicated in the survival of basal forebrain cholinergic neurons (BFCN) in development (Gnahn et al., 1983; Large et al., 1986; Mobley et al., 1986; Auburger et al., 1987; Crowley et al., 1994; Li et al., 1995; Fagan et al., 1997; Avignone et al., 1998; Tomioka et al., 2014) but not in the fully differentiated and mature CNS. In adulthood the presence of NGF is essential for the maintenance of the BFCN phenotype (Cuello, 1993) but not for their survival, even after extreme lesions of NGF-releasing nerve terminal sites (Sofroniew et al., 1990). The first evidence for NGF-reparative effects in the adult CNS came from studies applying axotomy of the fimbria fornix projection to deprive BFCN of target-derived NGF, which led to an apparent neuronal loss of cholinergic neurons of the medial septum (Hefti, 1986; Williams et al., 1986; Kromer, 1987).

In 1982, Whitehouse and collaborators proposed that the cortical cholinergic biochemical depletion in $\mathrm{AD}$ was due to the loss of magnocellular (presumed cholinergic) neurons of the nucleus basalis, based on Nissl studies in which only the large (magnocellular) neurons were counted (Whitehouse et al., 1982). Later assessments of choline acetyltransferase (ChAT) immunoreactivity in rodents demonstrated that large cortical stroke lesions, which eliminated cholinergic nerve terminals, resulted not in cell loss but rather in a loss of size and cholinergic character of the cholinergic neurons of the nucleus basalis (Sofroniew et al., 1983; Cuello et al., 1986). Furthermore, it was demonstrated that a similar atrophy of ChAT-immunoreactive neurons, rather than cell loss, was observed in the human nucleus basalis of Meynert in $\mathrm{AD}$ (Pearson et al., 1983). These observations led us to propose that in $\mathrm{AD}$, the primary pathology results in a secondary retrograde atrophy of cholinergic neurons of the nucleus basalis (Cuello and Sofroniew, 1984) which could be rescued by the application of exogenous mature NGF (mNGF), including the compensatory de novo cholinergic synaptogenesis of the remaining, nonlesioned, cortical tissue.

The most definitive experimental evidence for neuronal atrophy following NGF deprivation came from the excitotoxic elimination of NGF-producing neurons in the hippocampus, sparing cholinergic nerve terminals but nonetheless inducing a similar atrophy of NGF-dependent neurons of the BF (Sofroniew et al., 1990).

A number of thorough experimental studies confirmed the ability of exogenous NGF (both recombinant and isolated from the maxillary gland) to support NGF-dependent cholinergic nuclei of the BF (nucleus basalis and medial septum) following their disconnection from the sites of NGF production (Sofroniew et al., 1983; Sofroniew and Pearson, 1985; Stephens et al., 1985; Kromer, 1987; Hagg et al., 1988; Cuello et al., 1989, 1992; Koliatsos et al., 1990, 1991; Tuszynski et al., 1990; Fischer and Björklund, 1991; Maysinger et al., 1993; Garofalo and Cuello, 1994, 1995; Burgos et al., 1995; Hu et al., 1997) and also in models of aging (Fischer et al., 1987). Importantly, it was demonstrated that exogenous NGF could elicit a compensatory de novo cholinergic synaptogenesis in the remaining nonlesioned cortical tissue in the mature and fully differentiated CNS (Garofalo et al., 1992).

Our lab introduced the concept that the day-to-day expression of endogenous mNGF regulates the steady-state number of cortical cholinergic synapses (Debeir et al., 1999) and, in consequence, the maintenance of the "cholinergic tone." This is in line with the classical Hebbian notion that synaptic growth is a brain activity-dependent phenomenon (Hebb, 1949). Indeed, altering the availability of endogenous NGF by pharmacologically blocking its conversion from proNGF to mNGF or by preventing its degradation does lead to notable changes in the density of cortical cholinergic terminals (Allard et al., 2012) as well as in the size and phenotype of BF cholinergic cell bodies (Allard et al., 2018).

The transcription of major cholinergic markers has been shown to be dependent on the signaling of the NGF ligand through the NGF receptor TrkA; this includes the expression of TrkA itself (Venero et al., 1994; Figueiredo et al., 1995) as well as the acetylcholine synthesis enzyme ChAT and the vesicular acetylcholine transporter VAChT (Gnahn et al., 1983; Stephens et al., 1985; Hartikka and Hefti, 1988; Pongrac and Rylett, 1998; Berse et al., 1999; Madziar et al., 2005), which share a common locus and transcriptional regulation and are often considered together as the "cholinergic gene locus." In vitro experiments have shown that the ability of NGF to upregulate ChAT expression in BFCNs is enhanced by administration of gangliosides (Cuello et al., 1989) or with the co-culture of glial cells (Takei et al., 1988). Lastly, the extent of dendritic arbors, axon length, and the characteristic multipolarity of BF cholinergic cells have all been shown to be dependent on NGF (Hartikka and Hefti, 1988; Markova and Isaev, 1992).

Central to this process seems to be the homeobox transcription factor LIM homeobox 8, or Lhx8, the expression of which is essential for the development of BFCN (Mori et al., 2004). Lhx8 directly controls the expression of TrkA, is essential for normal release of acetylcholine, and is induced by NGF signaling through the ERK pathway (Tomioka et al., 2014). As ChAT and VAChT are downstream of TrkA, Lhx8 may function as a NGF-responsive master regulator of cholinergic character, both in development and in the adult organism. 


\section{POSSIBLE CLINICAL APPLICATION OF EXOGENOUS NGF}

As discussed above, there is abundant experimental literature supporting the ability of "exogenous" mNGF to recover atrophic $\mathrm{BFCN}$ in rodent lesion models as well as in non-human primates. Such strong experimental evidence provoked a number of clinical attempts to apply exogenous mNGF in the cerebroventricular space of AD patients (Jönhagen et al., 1998), attempts which were discontinued due to adverse off-target effects, specifically the induction of back pain by the sprouting of pain-conducting fibers in the spinal cord dorsal root ganglia.

Most recently, attempts to apply NGF therapeutically in the context of $\mathrm{AD}$ have employed gene therapy to overexpress the NGF gene (Tuszynski et al., 2005, 2015; Rafii et al., 2014) or the implantation of microencapsulated patientderived fibroblasts, genetically engineered to overproduce NGF (Eriksdotter-Jönhagen et al., 2012; Eyjolfsdottir et al., 2016). These have achieved some success, demonstrating, variously, increases in BFCN arborization, cortical glucose metabolism, and nicotinic binding as well as normalization of cholinergic markers in the CSF, and inconsistent reports of reductions in cognitive decline (Tuszynski et al., 2005, 2015; Eriksdotter-Jönhagen et al., 2012; Ferreira et al., 2015; Karami et al., 2015; Eyjolfsdottir et al., 2016). Ultimately, the gene therapy approach was discontinued after a Phase 2 study which, though well tolerated, demonstrated no effect on cognitive outcomes (Rafii et al., 2014), while the use of microencapsulated engineered fibroblasts awaits definitive assessments of clinical efficacy (see also "Innovative Therapy for AD" by Maria Eriksdotter in this issue).

While these approaches show great promise, the application of exogenous NGF will inevitably entail the risk of offtarget effects. Trophic NGF signaling is tightly constrained both in space (synaptic compartmentalization) and in time (activity dependence). NGF applied outside these parameters will not necessarily have the desired effect. Furthermore, any interruptions in NGF trafficking or excessive degradation of NGF in AD would not necessarily be overcome by exogenous application. An ideal approach would be to rather enhance the availability of endogenous NGF specifically at its physiological sites of synthesis, release, and signaling.

\section{ATROPHY OF BFCNS IN AD AND ITS CAUSES AND THE NGF PARADOX}

It is well established that BFCN are highly vulnerable to $\mathrm{AD}$ pathology, as they are observed in greatly reduced numbers at clinical presentation (Whitehouse et al., 1981). As discussed above, these neurons were initially presumed to have died (Whitehouse et al., 1981, 1982) but were later shown to persist in an atrophic state. The nucleus basalis of Meynert may be preferentially vulnerable compared to the medial septum and diagonal band (Mufson et al., 1989). The atrophy of the BFCN in AD correlates to disease duration (Mufson et al., 1989), amyloid load (Kerbler et al., 2015), and to cognitive status (Grothe et al., 2010), demonstrating that BFCN degeneration is tightly linked to amyloid accumulation and cognitive decline in early clinical $\mathrm{AD}$. These findings, in combination with the downregulation of cholinergic markers in $\mathrm{AD}$ and the amnesic effects of anticholinergic compounds in aged individuals (Drachman and Leavitt, 1974), led Bartus to formulate the much-quoted Cholinergic Hypothesis of Geriatric Memory Dysfunction (Bartus et al., 1982).

The cholinergic hypothesis has been mischaracterized in the intervening years, as researchers sought a contrast to the wellsupported and etiological amyloid hypothesis despite the fact that Coyle et al. (1983) made it clear in a Science review that the "Cholinergic Hypothesis of $\mathrm{AD}$ " meant a significant involvement of the cholinergic system in the pathology, and not causality. At about the same time, in a TINS review, we raised the possibility that the cholinergic atrophy could be secondary to a cortical lesion in AD (Cuello and Sofroniew, 1984) and Bartus et al. (1985) revised the status of "The Cholinergic Hypothesis," clarifying further that "it states nothing about etiological factors" but rather describes the role of cholinergic dysfunction in memory mechanisms. Nonetheless, the cholinergic hypothesis continues to be maligned as having "failed to cure AD." The cholinergic hypothesis led to the development of treatments, which have shown temporary cognitive benefits in patients (Adlimoghaddam et al., 2018; Birks and Harvey, 2018; Hampel et al., 2018). It is remarkable, given the widespread and irreversible brain damage already present at $\mathrm{AD}$ clinical presentation, that cholinergic therapy can still exert these beneficial cognitive effects.

After the publication of Bartus's paper, it was reasonably assumed that there should be a trophic NGF failure (Appel, 1981; Hefti, 1983) to explain the cholinergic deficit in AD, an issue provoking much attention at the time. However, paradoxically, it was shown that NGF mRNA is unchanged in AD (Goedert et al., 1986), and that NGF immunoreactivity is elevated (Crutcher et al., 1993; Scott et al., 1995; Fahnestock et al., 1996). When it was later demonstrated that the signal previously measured as NGF was in fact proNGF, i.e., the NGF precursor molecule (Fahnestock et al., 2001; Peng et al., 2004), which massively predominates in the brain, it remained an open question why the BF should deteriorate when the precursor to its trophic ligand is elevated.

\section{A NOVEL NGF METABOLIC PATHWAY AND ITS PHARMACOLOGICAL VALIDATION}

In light of the above, our laboratory investigated how mNGF was generated and released in the extracellular space by performing classical ex vivo superfusion of young rat cerebral cortex tissue (Bruno and Cuello, 2006). To our surprise, we found that, contrary to the prevalent dogma, proNGF (and not mNGF) was the molecular form released in an activity-dependent manner by cortical neurons ex vivo. We found that released proNGF is converted to mNGF and ultimately degraded by metalloproteases in the extracellular space. The conversion of proNGF into mNGF was found to be performed by plasmin, a serine-protease derived from plasminogen when cleaved by tissue plasminogen 

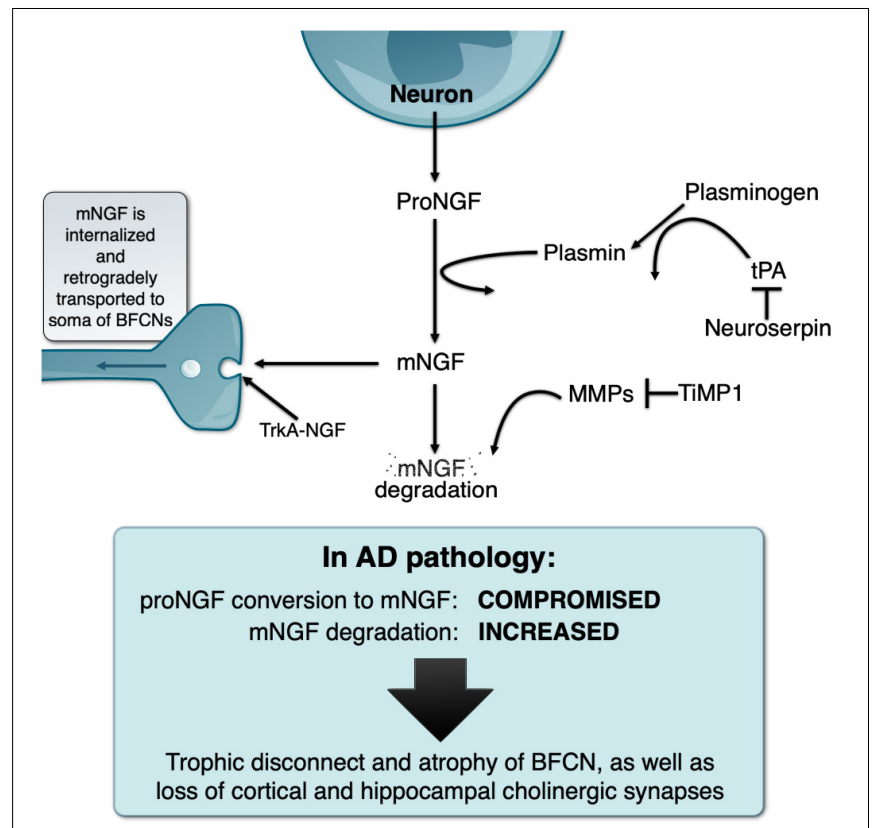

FIGURE 1 | Schematic representation of the NGF metabolic pathway under physiological conditions and its deregulation in the Alzheimer's pathology, explaining the "trophic disconnect" of NGF-dependent cholinergic neurons of the basal forebrain.

activator (tPA). This process is regulated by neuroserpin, the main inhibitor of tPA in the target regions of the BF cholinergic system (Krueger et al., 1997). Newly formed mNGF exists only transiently in the extracellular space as it binds to its cognate receptors (tropomysin receptor kinase A [TrkA] and p75NTR receptors) and is retrogradely transported to the cholinergic neurons cell somata where it exerts its trophic actions (Seiler and Schwab, 1984; Grimes et al., 1996, 1997; Figure 1).

We demonstrated that the non-internalized, extracellular remnants are likely to be degraded by activated matrixmetalloprotease 9 (MMP-9), a process controlled by tissue inhibitor of metalloproteinases 1 (TIMP-1). We also showed that the enzymes, zymogens, regulators, and inhibitors necessary for proNGF maturation and subsequent mNGF degradation are released simultaneously alongside proNGF in the extracellular space upon neuronal stimulation. The term NGF metabolic pathway was therefore coined to refer to this coordinated array of enzymatic conversions (Bruno and Cuello, 2006; Figure 1).

We further validated this pathway by demonstrating that pharmacological inhibition of the maturation or degradation enzymatic pathway can trigger proNGF/mNGF imbalances (Allard et al., 2012, 2018). In particular, continuous infusion of $\alpha 2$-antiplasmin, the endogenous inhibitor of plasmin, in the cerebral cortex of rats led to reduced levels of mNGF, which further led to cortical cholinergic synaptic atrophy. Conversely, infusion of MMP2-9 inhibitor induced an increase in mNGF levels by preventing its degradation, which was associated with cholinergic synaptic sprouting (Allard et al., 2012), thereby confirming the important role of the endogenous mNGF in the day-to-day maintenance of cholinergic synapses. In a further study, impaired proNGF cortical maturation following infusion of $\alpha 2$-antiplasmin was sufficient to alter BFCN phenotype. In particular, there was a significant atrophy of cell bodies as well as a downregulation of p75NTR and TrkA, and a reduction in the expression of ChAT protein, further validating the importance of the extracellular NGF metabolic pathway for the phenotypic maintenance of BFCN (Allard et al., 2018).

The experimental studies highlighted above reinforce the concept that imbalances in the NGF metabolic pathway can contribute to impairment of the $\mathrm{BF}$ cholinergic system, as seen in $\mathrm{AD}$ and down syndrome (DS), thereby providing a platform to investigate $\mathrm{AD}$ pathogenesis through the NGF pathway perspective.

\section{THE NGF METABOLIC PATHWAY IN AD AND IN DS WITH AD PATHOLOGY}

Following the discovery and validation of the NGF metabolic pathway, we applied this paradigm to the study of human brain material in $\mathrm{AD}$ and $\mathrm{DS}$, both of which exhibit a marked atrophy of the NGF-dependent BF cholinergic system. In AD brains, proNGF levels are increased (Peng et al., 2004) while NGF biosynthesis is normal (Goedert et al., 1986). However, we demonstrated that there is in fact a compromise in the conversion of proNGF to biologically active mNGF as well as a likely exacerbated degradation of mNGF (Bruno et al., 2009a), therefore explaining that a trophic failure is responsible for the cholinergic atrophy in $\mathrm{AD}$. In addition, at the mild cognitive impairment (MCI) stage (a prodromal stage of AD), the pathway is already compromised and shows increased MMP9 activity, which would facilitate the degradation of mNGF (Bruno et al., 2009b). This would suggest that the NGF dysfunction appears early in the course of the disease, before or concurrent with the earliest cognitive impairment and may constitute a relevant therapeutic target.

As individuals with DS inexorably develop AD neuropathology (Head and Lott, 2004), we investigated in DS genetic models, fetal cortical cells and post-mortem brain samples, whether the AD pathology in DS impaired the NGF metabolic pathway. These studies eloquently illustrated a compromise of the NGF metabolic pathway responsible for the conversion of proNGF to $\mathrm{mNGF}$ in DS brains with AD pathology. Levels of plasmin and tPA mRNA were reduced, preventing proNGF maturation and resulting in the pathological brain buildup of proNGF. DS brains also exhibited elevated zymogenic activity of MMP9, thereby exacerbating the degradation of the limited amount of available biologically active mNGF (Iulita et al., 2014). These results have been further reviewed in (Iulita and Cuello, 2016; Iulita et al., 2016a).

In a further extension, levels of key members of the NGF metabolic cascade, inflammatory mediators and $\mathrm{A} \beta$ peptides were assessed in plasma samples from a clinically characterized cohort of DS individuals, longitudinally followed for 2 years. Levels of proNGF, MMP-1 and MMP-3, and MMP-9 activity were even elevated at $\mathrm{AD}$ asymptomatic stages. In addition, this 
study provided compelling evidence that DS/AD asymptomatic individuals showing elevation of plasma proNGF levels at the 1year follow-up experienced a greater cognitive deterioration the subsequent year. Furthermore, in DS individuals of advanced age there was a strong correlation between brain amyloid-beta $(A \beta)$ load and the elevation of proNGF, strengthening the association between $A \beta$ and NGF metabolic pathway dysfunction (Iulita et al., 2016b). A similar progressive deregulation of the NGF metabolic pathway has been found in transgenic rats modeling the AD-like amyloid pathology (Iulita et al., 2017; Figure 1).

\section{NOVEL DEVELOPMENTS REGARDING THE IMPLICATION OF THE CHOLINERGIC SYSTEM IN AD}

New developments, such as the ones highlighted above, have led to a renewed interest regarding the neurobiology of the $\mathrm{BF}$ cholinergic system in health and in neurodegenerative conditions. Recent observations note that long term treatment with donepezil, one of the leading acetylcholine esterase inhibitors (AChEis) (elevating the "cholinergic tone") used for its symptomatic cognitive benefits in $\mathrm{AD}$, was shown to reduce the rate of change in regional cortical thickness in individuals suspected of prodromal AD (Cavedo et al., 2016) as well as diminish the rate of hippocampal (Dubois et al., 2015) and BF atrophy in prodromal AD (Cavedo et al., 2017).

Conversely, recent studies provide evidence of brain atrophy and increased risk of dementia and $\mathrm{AD}$ in non-demented individuals receiving long term (over 3 years) medications with drugs possessing primary or secondary anti-cholinergic properties (Jessen et al., 2010; Gray and Hanlon, 2016; Risacher et al., 2016; Chuang et al., 2017). In particular, there is consistent evidence for increased risk of dementia in the elderly receiving defined anticholinergic compounds (Gray and Hanlon, 2018). In addition, low doses of the muscarinic antagonist scopolamine leads to poor cognitive performance in individuals revealing a posteriori AD-like brain amyloid burden (Snyder et al., 2014, 2015).

It is also interesting to note that a study from the Alzheimer's disease neuroimaging initiative (ADNI) revealed that in humans the atrophy of the BF nucleus basalis of Meynert precedes and predicts memory impairment and the extent of cortical spread of the Alzheimer's pathology (Schmitz et al., 2016). In further extensions, these studies indicate that atrophy of the BF covaries with the cortical thinning and loss of PET-identified cholinergic projections to cortical regions (Schmitz et al., 2018) and that BF volume predicts rate of global cognitive deterioration better than hippocampal volume (Teipel et al., 2018). These studies therefore reaffirm that the $\mathrm{BFCN}$ are central to the $\mathrm{AD}$ pathology and its cognitive outcomes. This concept is frequently questioned by the fact that cholinergic therapy only provides modest and transient cognitive relief in $\mathrm{AD}$. As such, it should be noted that novel drugs targeting the cholinergic system, beyond the cholinesterase inhibitors approved for the symptomatic treatment of $\mathrm{AD}$, are emerging as therapeutic tools, in particular muscarinic receptor agonists (Fisher, 2012; Verma et al., 2018). In particular, a combined M1 muscarinic-sigma 1 receptor was shown to have a remarkable effect in diminishing amyloid pathology and the associated cognitive impairment in a transgenic rat model of ADlike amyloid pathology, even after a treatment "wash-out" of a month (equivalent to 3 years of human life) (Hall et al., 2018).

The above strongly suggest that trophic preservation of BF cholinergic neurons (i.e., normalization of the NGF metabolic pathway) could constitute an effective avenue to achieve diseasemodifying effects. An appropriate therapeutic window for such an approach should lie at pre-symptomatic stages of $\mathrm{AD}$, before the cholinergic system is compromised beyond repair. Such goals await the development of biomarkers defining unequivocally a progressing $\mathrm{AD}$ pathology before its clinical presentation.

\section{CONCLUSION AND FUTURE CHALLENGES}

This discussion paper highlights the significance of the NGF metabolic pathway for the maintenance of a healthy phenotype of BFCN and synapses, a system key for higher CNS functions. It illustrates how the compromise of this pathway likely underlies the atrophy of BFCN in AD (see Figure 1).

Recent clinical data would indicate that these trophic mechanisms might not necessarily be unidirectional, as the current NGF dogma indicates. Future studies may reveal novel insights into possible reciprocal interactions between the $\mathrm{BF}$ cholinergic system and the NGF metabolic pathway, both in physiological and pathological conditions. Further to it, research on such trophic interactions could help identify novel biomarkers signaling a progressive preclinical $\mathrm{AD}$ pathology and pave the way for novel therapeutic interventions for $\mathrm{AD}$ and associated pathologies with NGF cholinergic involvement.

\section{AUTHOR CONTRIBUTIONS}

ACC, RP, and HH wrote and edited the manuscript. All authors approved it for publication.

\section{FUNDING}

This work was funded by the Canadian Institutes of Health and Research (CIHR) Project Grant (201603PJT-364544) to ACC and by the National Institute of Health and Aging Operating Grant (R01-AG056850) to ACC. ACC was the holder of the Charles E. Frosst/Merck endowed Chair in Pharmacology and a member of the Canadian consortium on Neurodegeneration in Aging. RP was the recipient of a CIHR fellowship (201610MDR-380389Doctoral Research Award).

\section{ACKNOWLEDGMENTS}

The authors are grateful for the unrestricted support provided by Merck Canada. The authors also acknowledge Janice Malcolm for the artwork of Figure 1. 


\section{REFERENCES}

Adlimoghaddam, A., Neuendorff, M., Roy, B., and Albensi, B. C. (2018). A review of clinical treatment considerations of donepezil in severe Alzheimer's disease. CNS Neurosci. Therapeut. 24, 876-888. doi: 10.1111/cns.13035

Allard, S., Jacobs, M. L., Do Carmo, S., and Cuello, A. C. (2018). Compromise of cortical proNGF maturation causes selective retrograde atrophy in cholinergic nucleus basalis neurons. Neurobiol. Aging 67, 10-20. doi: 10.1016/j. neurobiolaging.2018.03.002

Allard, S., Leon, W. C., Pakavathkumar, P., Bruno, M. A., Ribeiro-da-Silva, A., and Cuello, A. C. (2012). Impact of the NGF maturation and degradation pathway on the cortical cholinergic system phenotype. J. Neurosci. 32, 2002-2012. doi: 10.1523/JNEUROSCI.1144-11.2012

Appel, S. H. (1981). A unifying hypothesis for the cause of amyotrophic lateral sclerosis, parkinsonism, and Alzheimer disease. Ann. Neurol. 10, 499-505. doi: 10.1002/ana.410100602

Auburger, G., Heumann, R., Hellweg, R., Korsching, S., and Thoenen, H. (1987). Developmental changes of nerve growth factor and its mRNA in the rat hippocampus: comparison with choline acetyltransferase. Dev. Biol. 120, 322328. doi: 10.1016/0012-1606(87)90235-1

Avignone, E., Molnar, M., Berretta, N., Casamenti, F., Prosperi, C., Ruberti, F., et al. (1998). Cholinergic function in the hippocampus of juvenile rats chronically deprived of NGF. Dev. Brain Res. 109, 137-147. doi: 10.1016/S0165-3806(98) 00072-8

Bartus, R. T., Dean, R. L. III, Beer, B., and Lippa, A. S. (1982). The cholinergic hypothesis of geriatric memory dysfunction. Science 217, 408-414. doi: 10.1126/ science.7046051

Bartus, R. T., Dean, R. L., Pontecorvo, M. J., and Flicker, C. (1985). The cholinergic hypothesis: a historical overview, current perspective, and future directions. Ann. N. Y. Acad. Sci. 444, 332-358. doi: 10.1111/j.1749-6632.1985.tb 37600.x

Berse, B., Lopez-Coviella, I., and Blusztajn, J. K. (1999). Activation of TrkA by nerve growth factor upregulates expression of the cholinergic gene locus but attenuates the response to ciliary neurotrophic growth factor. Biochem. J. 342, 301-308. doi: 10.1042/bj3420301

Birks, J. S., and Harvey, R. J. (2018). Donepezil for dementia due to Alzheimer's disease. Cochrane Database Syst. Rev. CD001190. doi: 10.1002/14651858. CD001190.pub3

Bruno, M. A., and Cuello, A. C. (2006). Activity-dependent release of precursor nerve growth factor, conversion to mature nerve growth factor, and its degradation by a protease cascade. Proc. Natl. Acad. Sci. U.S.A. 103, 6735-6740. doi: 10.1073/pnas.0510645103

Bruno, M. A., Leon, W. C., Fragoso, G., Mushynski, W. E., Almazan, G., and Cuello, A. C. (2009a). Amyloid $\beta$-induced nerve growth factor dysmetabolism in Alzheimer disease. J. Neuropathol. Exp. Neurol. 68, 857-869. doi: 10.1097/ NEN.0b013e3181aed9e6

Bruno, M. A., Mufson, E. J., Wuu, J., and Cuello, A. C. (2009b). Increased Matrix Metalloproteinase-9 activity in mild cognitive impairment. J. Neuropathol. Exp. Neurol. 68, 1309. doi: 10.1097/NEN.0b013e3181c22569

Burgos, I., Cuello, A. C., Liberini, P., Pioro, E., and Masliah, E. (1995). NGFmediated synaptic sprouting in the cerebral cortex of lesioned primate brain. Brain Res. 692, 154-160. doi: 10.1016/0006-8993(95)00696-N

Cavedo, E., Dubois, B., Colliot, O., Lista, S., Croisile, B., Tisserand, G. L., et al. (2016). Reduced regional cortical thickness rate of change in donepezil-treated subjects with suspected prodromal Alzheimer's disease. J. Clin. Psychiatry 77, e1631-e1638. doi: 10.4088/JCP.15m10413

Cavedo, E., Grothe, M. J., Colliot, O., Lista, S., Chupin, M., Dormont, D., et al. (2017). Reduced basal forebrain atrophy progression in a randomized Donepezil trial in prodromal Alzheimer's disease. Sci. Rep. 7:11706. doi: 10. 1038/s41598-017-09780-3

Chuang, Y.-F., Elango, P., Gonzalez, C. E., and Thambisetty, M. (2017). Midlife anticholinergic drug use, risk of Alzheimer's disease, and brain atrophy in community-dwelling older adults. Alzheimer's Dementia: Transl. Res. Clin. Intervent. 3, 471-479. doi: 10.1016/j.trci.2017.06.004

Cohen, S., Levi-Montalcini, R., and Hamburger, V. (1954). A nerve growthstimulating factor isolated from sarcom as 37 and 180. Proc. Natl. Acad. Sci. U.S.A. 40, 1014-1018. doi: 10.1073/pnas.40.10.1014
Cowan, W. M. (2001). Viktor hamburger and rita levi-montalcini: the path to the discovery of nerve growth factor. Annu. Rev. Neurosci. 24, 551-600. doi: 10.1146/annurev.neuro.24.1.551

Coyle, J. T., Price, D. L., and DeLong, M. R. (1983). Alzheimer's disease: a disorder of cortical cholinergic innervation. Science 219, 1184-1190. doi: 10. 1126/science.6338589

Crowley, C., Spencer, S. D., Nishimura, M. C., Chen, K. S., Pitts-Meek, S., Armaninl, M. P., et al. (1994). Mice lacking nerve growth factor display perinatal loss of sensory and sympathetic neurons yet develop basal forebrain cholinergic neurons. Cell 76, 1001-1011. doi: 10.1016/0092-8674(94)90378-6

Crutcher, K. A., Scott, S. A., Liang, S., Everson, W. V., and Weingartner, J. (1993). Detection of NGF-like activity in human brain tissue: increased levels in Alzheimer's disease. J. Neurosci. 13, 2540-2550. doi: 10.1523/JNEUROSCI. 13-06-02540.1993

Cuello, A., Garofalo, L., Kenigsberg, R., and Maysinger, D. (1989). Gangliosides potentiate in vivo and in vitro effects of nerve growth factor on central cholinergic neurons. Proc. Natl. Acad. Sci. U.S.A. 86, 2056-2060. doi: 10.1073/ pnas.86.6.2056

Cuello, A., Maysinger, D., and Garofalo, L. (1992). Trophic factor effects on cholinergic innervation in the cerebral cortex of the adult rat brain. Mol. Neurobiol. 6, 451-461. doi: 10.1007/BF02757946

Cuello, A., Stephens, P., Tagari, P., Sofroniew, M., and Pearson, R. (1986). Retrograde changes in the nucleus basalis of the rat, caused by cortical damage, are prevented by exogenous ganglioside GM1. Brain Res. 376, 373-377. doi: 10.1016/0006-8993(86)90202-7

Cuello, A. C. (1993). Trophic responses of forebrain cholinergic neurons. Progr. Brain Res. 98, 265-265. doi: 10.1016/S0079-6123(08)62408-5

Cuello, A. C., and Sofroniew, M. V. (1984). The anatomy of the CNS cholinergic neurons. Trends Neurosci. 7, 74-78. doi: 10.1016/S0166-2236(84)80161-7

Debeir, T., Saragovi, H. U., and Cuello, A. C. (1999). A nerve growth factor mimetic TrkA antagonist causes withdrawal of cortical cholinergic boutons in the adult rat. Proc. Natl. Acad. Sci. U.S.A. 96, 4067-4072. doi: 10.1073/pnas.96.7.4067

Drachman, D. A., and Leavitt, J. (1974). Human memory and the cholinergic system: a relationship to aging? Arch. Neurol. 30, 113-121. doi: 10.1001/ archneur.1974.00490320001001

Dubois, B., Chupin, M., Hampel, H., Lista, S., Cavedo, E., Croisile, B., et al. (2015). Donepezil decreases annual rate of hippocampal atrophy in suspected prodromal Alzheimer's disease. Alzheimer's Dementia 11, 1041-1049. doi: 10. 1016/j.jalz.2014.10.003

Eriksdotter-Jönhagen, M., Linderoth, B., Lind, G., Aladellie, L., Almkvist, O., Andreasen, N., et al. (2012). Encapsulated cell biodelivery of nerve growth factor to the basal forebrain in patients with Alzheimer's disease. Dementia Geriatr. Cognit. Disord. 33, 18-28. doi: 10.1159/000336051

Eyjolfsdottir, H., Eriksdotter, M., Linderoth, B., Lind, G., Juliusson, B., Kusk, P., et al. (2016). Targeted delivery of nerve growth factor to the cholinergic basal forebrain of Alzheimer's disease patients: application of a second-generation encapsulated cell biodelivery device. Alzheimer's Res. Ther. 8:30. doi: 10.1186/ s13195-016-0195-9

Fagan, A. M., Garber, M., Barbacid, M., Silos-Santiago, I., and Holtzman, D. M. (1997). A role for TrkA during maturation of striatal and basal forebrain cholinergic neurons in vivo. J. Neurosci. 17, 7644-7654. doi: 10.1523/ JNEUROSCI.17-20-07644.1997

Fahnestock, M., Michalski, B., Xu, B., and Coughlin, M. D. (2001). The precursor pro-nerve growth factor is the predominant form of nerve growth factor in brain and is increased in Alzheimer's disease. Mol. Cell Neurosci. 18, 210-220. doi: $10.1006 /$ mcne. 2001.1016

Fahnestock, M., Scott, S. A., Jette, N., Weingartner, J. A., and Crutcher, K. A. (1996). Nerve growth factor mRNA and protein levels measured in the same tissue from normal and Alzheimer's disease parietal cortex. Brain Res. Mol. Brain Res. 42, 175-178. doi: 10.1016/S0169-328X(96)00193-3

Ferreira, D., Westman, E., Eyjolfsdottir, H., Almqvist, P., Lind, G., Linderoth, B., et al. (2015). Brain changes in Alzheimer's disease patients with implanted encapsulated cells releasing nerve growth factor. J. Alzheimer's Dis. 43, 10591072. doi: 10.3233/JAD- 141068

Figueiredo, B., Skup, M., Bedard, A., Tetzlaff, W., and Cuello, A. (1995). Differential expression of p140trk, p75NGFR and growth-associated phosphoprotein-43 genes in nucleus basalis magnocellularis, thalamus 
and adjacent cortex following neocortical infarction and nerve growth factor treatment. Neuroscience 68, 29-45. doi: 10.1016/0306-4522(95)91510-J

Fischer, W., and Björklund, A. (1991). Loss of AChE-and NGFr-labeling precedes neuronal death of axotomized septal-diagonal band neurons: reversal by intraventricular NGF infusion. Exp. Neurol. 113, 93-108. doi: 10.1016/00144886(91)90167-B

Fischer, W., Wictorin, K., Björklund, A., Williams, L., Varon, S., and Gage, F. (1987). Amelioration of cholinergic neuron atrophy and spatial memory impairment in aged rats by nerve growth factor. Nature 329:65. doi: 10.1038/ $329065 \mathrm{a} 0$

Fisher, A. (2012). Cholinergic modulation of amyloid precursor protein processing with emphasis on M1 muscarinic receptor: perspectives and challenges in treatment of Alzheimer's disease. J. Neurochem. 120(Suppl. 1), 22-33. doi: 10. 1111/j.1471-4159.2011.07507.x

Garofalo, L., and Cuello, A. (1994). Nerve growth factor and the monosialoganglioside GM1: analogous and different in vivo effects on biochemical, morphological, and behavioral parameters of adult cortically lesioned rats. Exp. Neurol. 125, 195-217. doi: 10.1006/exnr.1994.1024

Garofalo, L., and Cuello, A. C. (1995). Pharmacological characterization of nerve growth factor and/or monosialoganglioside GM1 effects on cholinergic markers in the adult lesioned brain. J. Pharmacol. Exp. Therapeut. 272, 527-545.

Garofalo, L., Ribeiro-da-Silva, A., and Cuello, A. C. (1992). Nerve growth factorinduced synaptogenesis and hypertrophy of cortical cholinergic terminals. Proc. Natl. Acad. Sci. U.S.A. 89, 2639-2643. doi: 10.1073/pnas.89.7.2639

Gnahn, H., Hefti, F., Heumann, R., Schwab, M., and Thoenen, H. (1983). NGFmediated increase of choline acetyltransferase (ChAT) in the neonatal rat forebrain: evidence for a physiological role of NGF in the brain? Dev. Brain Res. 9, 45-52. doi: 10.1016/0165-3806(83)90107-4

Goedert, M., Fine, A., Hunt, S., and Ullrich, A. (1986). Nerve growth factor mRNA in peripheral and central rat tissues and in the human central nervous system: lesion effects in the rat brain and levels in Alzheimer's disease. Mol. Brain Res. 1, 85-92. doi: 10.1016/0169-328X(86)90023-9

Gray, S. L., and Hanlon, J. T. (2016). Anticholinergic medication use and dementia: latest evidence and clinical implications. Ther. Adv. Drug Saf. 7, 217-224. doi: $10.1177 / 2042098616658399$

Gray, S. L., and Hanlon, J. T. (2018). Anticholinergic drugs and dementia in older adults. BMJ 361:k1722. doi: 10.1136/bmj.k1722

Grimes, M. L., Beattie, E., and Mobley, W. C. (1997). A signaling organelle containing the nerve growth factor-activated receptor tyrosine kinase, TrkA. Proc. Natl. Acad. Sci. U.S.A. 94, 9909-9914. doi: 10.1073/pnas.94.18.9909

Grimes, M. L., Zhou, J., Beattie, E. C., Yuen, E. C., Hall, D. E., Valletta, J. S., et al. (1996). Endocytosis of activated TrkA: evidence that nerve growth factor induces formation of signaling endosomes. J. Neurosci. 16, 7950-7964. doi: 10.1523/JNEUROSCI.16-24-07950.1996

Grothe, M., Zaborszky, L., Atienza, M., Gil-Neciga, E., Rodriguez-Romero, R., Teipel, S. J., et al. (2010). Reduction of basal forebrain cholinergic system parallels cognitive impairment in patients at high risk of developing Alzheimer's disease. Cereb. Cortex 20, 1685-1695. doi: 10.1093/cercor/bhp232

Hagg, T., Manthorpe, M., Vahlsing, H. L., and Varon, S. (1988). Delayed treatment with nerve growth factor reverses the apparent loss of cholinergic neurons after acute brain damage. Exp. Neurol. 101, 303-312. doi: 10.1016/0014-4886(88) 90013-1

Hall, H., Iulita, M. F., Gubert, P., Flores Aguilar, L., Ducatenzeiler, A., Fisher, A., et al. (2018). AF710B, an M1/sigma-1 receptor agonist with long-lasting disease-modifying properties in a transgenic rat model of Alzheimer's disease. Alzheimers Dement 14, 811-823. doi: 10.1016/j.jalz.2017.11.009

Hampel, H., Mesulam, M.-M., Cuello, A. C., Farlow, M. R., Giacobini, E., Grossberg, G. T., et al. (2018). The cholinergic system in the pathophysiology and treatment of Alzheimer's disease. Brain 141, 1917-1933. doi: 10.1093/brain/ awy132

Hartikka, J., and Hefti, F. (1988). Development of septal cholinergic neurons in culture: plating density and glial cells modulate effects of NGF on survival, fiber growth, and expression of transmitter-specific enzymes. J. Neurosci. 8, 2967-2985. doi: 10.1523/JNEUROSCI.08-08-02967.1988

Head, E., and Lott, I. T. (2004). Down syndrome and beta-amyloid deposition. Curr. Opin. Neurol. 17, 95-100. doi: 10.1097/00019052-200404000-00003

Hebb, D. O. (1949). The Organization of Behavior: A Neuropsychological Theory. Hoboken, NJ: Wiley.
Hefti, F. (1983). Is Alzheimer disease caused by lack of nerve growth factor? Ann. Neurol. 13, 109-110. doi: 10.1002/ana.410130127

Hefti, F. (1986). Nerve growth factor promotes survival of septal cholinergic neurons after fimbrial transections. J. Neurosci. 6, 2155-2162. doi: 10.1523/ JNEUROSCI.06-08-02155.1986

Hu, L., Côté, S. L., and Cuello, A. C. (1997). Differential modulation of the cholinergic phenotype of the nucleus basalis magnocellularis neurons by applying NGF at the cell body or cortical terminal fields. Exp. Neurol. 143, 162-171. doi: 10.1006/exnr.1996.6357

Iulita, M. F., Bistue Millon, M. B., Pentz, R., Aguilar, L. F., Do Carmo, S., Allard, S., et al. (2017). Differential deregulation of NGF and BDNF neurotrophins in a transgenic rat model of Alzheimer's disease. Neurobiol. Dis. 108, 307-323. doi: 10.1016/j.nbd.2017.08.019

Iulita, M. F., Caraci, F., and Cuello, A. C. (2016a). A link between nerve growth factor metabolic deregulation and amyloid- $\beta$-driven inflammation in down syndrome. CNS Neurol. Disord. Drug Targets 15, 434-447. doi: 10.2174/ 1871527315666160321104916

Iulita, M. F., Ower, A., Barone, C., Pentz, R., Gubert, P., Romano, C., et al. (2016b). An inflammatory and trophic disconnect biomarker profile revealed in Down syndrome plasma: relation to cognitive decline and longitudinal evaluation. Alzheimer's Dementia 12, 1132-1148. doi: 10.1016/j.jalz.2016.05.001

Iulita, M. F., and Cuello, A. C. (2016). The NGF metabolic pathway in the CNS and its dysregulation in down syndrome and Alzheimer's disease. Curr. Alzheimer Res. 13, 53-67. doi: 10.2174/1567205012666150921100030

Iulita, M. F., Do Carmo, S., Ower, A., Fortress, A., Flores Aguilar, L., Hanna, M., et al. (2014). Nerve growth factor metabolic dysfunction in Down's syndrome brains. Brain 137(Pt 3), 860-872. doi: 10.1093/brain/awt372

Jessen, F., Kaduszkiewicz, H., Daerr, M., Bickel, H., Pentzek, M., Riedel-Heller, S., et al. (2010). Anticholinergic drug use and risk for dementia: target for dementia prevention. Eur. Arch. Psychiatry Clin. Neurosci. 260(Suppl. 2), S111-S115. doi: 10.1007/s00406-010-0156-4

Jönhagen, M. E., Nordberg, A., Amberla, K., Bäckman, L., Ebendal, T., Meyerson, B., et al. (1998). Intracerebroventricular infusion of nerve growth factor in three patients with Alzheimer's disease. Dementia Geriatr. Cognit. Disord. 9, 246-257. doi: 10.1159/000017069

Karami, A., Eyjolfsdottir, H., Vijayaraghavan, S., Lind, G., Almqvist, P., Kadir, A., et al. (2015). Changes in CSF cholinergic biomarkers in response to cell therapy with NGF in patients with Alzheimer's disease. Alzheimer's Dementia 11, 1316-1328. doi: 10.1016/j.jalz.2014.11.008

Kerbler, G. M., Fripp, J., Rowe, C. C., Villemagne, V. L., Salvado, O., Rose, S., et al. (2015). Basal forebrain atrophy correlates with amyloid $\beta$ burden in Alzheimer's disease. NeuroImage 7, 105-113. doi: 10.1016/j.nicl.2014.11.015

Koliatsos, V. E., Applegate, M. D., Knüsel, B., Junard, E. O., Burton, L. E., Mobley, W. C., et al. (1991). Recombinant human nerve growth factor prevents retrograde degeneration of axotomized basal forebrain cholinergic neurons in the rat. Exp. Neurol. 112, 161-173. doi: 10.1016/0014-4886(91)90066-L

Koliatsos, V. E., Nauta, H., Clatterbuck, R. E., Holtzman, D. M., Mobley, W. C., and Price, D. L. (1990). Mouse nerve growth factor prevents degeneration of axotomized basal forebrain cholinergic neurons in the monkey. J. Neurosci. 10, 3801-3813. doi: 10.1523/JNEUROSCI.10-12-03801.1990

Kromer, L. F. (1987). Nerve growth factor treatment after brain injury prevents neuronal death. Science 235, 214-216. doi: 10.1126/science. 3798108

Krueger, S. R., Ghisu, G.-P., Cinelli, P., Gschwend, T. P., Osterwalder, T., Wolfer, D. P., et al. (1997). Expression of neuroserpin, an inhibitor of tissue plasminogen activator, in the developing and adult nervous system of the mouse. J. Neurosci. 17, 8984-8996. doi: 10.1523/JNEUROSCI.17-23-08984. 1997

Large, T. H., Bodary, S. C., Clegg, D. O., Weskamp, G., Otten, U., and Reichardt, L. F. (1986). Nerve growth factor gene expression in the developing rat brain. Science 234, 352-355. doi: 10.1126/science.376 4415

Li, Y., Holtzman, D., Kromer, L., Kaplan, D., Chua-Couzens, J., Clary, D., et al. (1995). Regulation of TrkA and ChAT expression in developing rat basal forebrain: evidence that both exogenous and endogenous NGF regulate differentiation of cholinergic neurons. J. Neurosci. 15, 2888-2905. doi: 10.1523/ JNEUROSCI.15-04-02888.1995

Madziar, B., Lopez-Coviella, I., Zemelko, V., and Berse, B. (2005). Regulation of cholinergic gene expression by nerve growth factor depends on the 
phosphatidylinositol-3'-kinase pathway. J. Neurochem. 92, 767-779. doi: 10. 1111/j.1471-4159.2004.02908.x

Markova, E., and Isaev, N. (1992). Effects of nerve growth factor on the development of the dendritic system of cholinergic neurons in dissociated culture of the rat septum. Biull. Eksp. Biol. Med. 113, 318-320.

Maysinger, D., Piccardo, P., Filipovic-Grcic, J., and Cuello, A. (1993). Microencapsulation of genetically engineered fibroblasts secreting nerve growth factor. Neurochem. Int. 23, 123-129. doi: 10.1016/0197-0186(93) 90089-N

Mobley, W. C., Rutkowski, J. L., Tennekoon, G. I., Gemski, J., Buchanan, K., and Johnston, M. V. (1986). Nerve growth factor increases choline acetyltransferase activity in developing basal forebrain neurons. Mol. Brain Res. 1, 53-62. doi: 10.1016/0169-328X(86)90020-3

Mori, T., Yuxing, Z., Takaki, H., Takeuchi, M., Iseki, K., Hagino, S., et al. (2004). The LIM homeobox gene, L3/Lhx8, is necessary for proper development of basal forebrain cholinergic neurons. Eur. J. Neurosci. 19, 3129-3141. doi: 10.1111/j. 0953-816X.2004.03415.x

Mufson, E. J., Bothwell, M., and Kordower, J. H. (1989). Loss of nerve growth factor receptor-containing neurons in Alzheimer's disease: a quantitative analysis across subregions of the basal forebrain. Exp. Neurol. 105, 221-232. doi: 10. 1016/0014-4886(89)90124-6

Newmark, P. (1986). Nobel Prizes: Growth Factors Bring Rewards. London: Nature Publishing Group.

Pearson, R., Sofroniew, M., Cuello, A., Powell, T., Eckenstein, F., Esiri, M., et al. (1983). Persistence of cholinergic neurons in the basal nucleus in a brain with senile dementia of the Alzheimer's type demonstrated by immunohistochemical staining for choline acetyltransferase. Brain Res. 289, 375-379. doi: 10.1016/ 0006-8993(83)90046-X

Peng, S., Wuu, J., Mufson, E. J., and Fahnestock, M. (2004). Increased proNGF levels in subjects with mild cognitive impairment and mild Alzheimer disease. J. Neuropathol. Exp. Neurol. 63, 641-649. doi: 10.1093/jnen/63.6.641

Pongrac, J. L., and Rylett, R. J. (1998). NGF-induction of the expression of ChAT mRNA in PC12 cells and primary cultures of embryonic rat basal forebrain. Mol. Brain Res. 62, 25-34. doi: 10.1016/S0169-328X(98)00215-0

Rafii, M. S., Baumann, T. L., Bakay, R. A., Ostrove, J. M., Siffert, J., Fleisher, A. S., et al. (2014). A phasel study of stereotactic gene delivery of AAV2-NGF for Alzheimer's disease. Alzheimer's Dementia 10, 571-581. doi: 10.1016/j.jalz.2013. 09.004

Risacher, S. L., McDonald, B. C., Tallman, E. F., West, J. D., Farlow, M. R., Unverzagt, F. W., et al. (2016). Association between anticholinergic medication use and cognition, brain metabolism, and brain atrophy in cognitively normal older adults. JAMA Neurol. 73, 721-732. doi: 10.1001/jamaneurol.2016.0580

Schmitz, T. W., Mur, M., Aghourian, M., Bedard, M. -A., Spreng, R. N., and Initiative, A. S. D. N. (2018). Longitudinal Alzheimer's degeneration reflects the spatial topography of cholinergic basal forebrain projections. Cell Rep. 24, 38-46. doi: 10.1016/j.celrep.2018.06.001

Schmitz, T. W., Spreng, R. N., Weiner, M. W., Aisen, P., Petersen, R., Jack, C. R., et al. (2016). Basal forebrain degeneration precedes and predicts the cortical spread of Alzheimer's pathology. Nat. Commun. 7:13249. doi: 10.1038/ ncomms 13249

Scott, S. A., Mufson, E. J., Weingartner, J. A., Skau, K. A., and Crutcher, K. A. (1995). Nerve growth factor in Alzheimer's disease: increased levels throughout the brain coupled with declines in nucleus basalis. J. Neurosci. 15, 6213-6221. doi: 10.1523/JNEUROSCI.15-09-06213.1995

Seiler, M., and Schwab, M. E. (1984). Specific retrograde transport of nerve growth factor (NGF) from neocortex to nucleus basalis in the rat. Brain Res. 300, 33-39. doi: 10.1016/0006-8993(84)91338-6

Snyder, P. J., Lim, Y.-Y., Maruff, P., Schindler, R., Ott, B. R., Salloway, S., et al. (2015). Disruption of cholinergic neurotransmission unmasks aß-related cognitive impairment in preclinical Alzheimer's disease. Alzheimer's Dementia J. Alzheimer's Assoc. 11, 129-130. doi: 10.1016/j.jalz.2015.07.040

Snyder, P. J., Lim, Y. Y., Schindler, R., Ott, B. R., Salloway, S., Daiello, L., et al. (2014). Microdosing of scopolamine as a "cognitive stress test": rationale and test of a very low dose in an at-risk cohort of older adults. Alzheimer's Dementia 10, 262-267. doi: 10.1016/j.jalz.2014.01.009

Sofroniew, M., and Pearson, R. (1985). Degeneration of cholinergic neurons in the basal nucleus following kainic or N-methyl-D-aspartic acid application to the cerebral cortex in the rat. Brain Res. 339, 186-190. doi: 10.1016/0006-8993(85) 90643-2

Sofroniew, M., Pearson, R., Eckenstein, F., Cuello, A., and Powell, T. (1983). Retrograde changes in cholinergic neurons in the basal forebrain of the rat following cortical damage. Brain Res. 289, 370-374. doi: 10.1016/0006-8993(83) 90045-8

Sofroniew, M. V., Galletly, N. P., Isacson, O., and Svendsen, C. N. (1990). Survival of adult basal forebrain cholinergic neurons after loss of target neurons. Science 247, 338-342. doi: 10.1126/science.1688664

Stephens, P., Cuello, A., Sofroniew, M., Pearson, R., and Tagari, P. (1985). Effect of unilateral decortication on choline acetyltransferase activity in the nucleus basalis and other areas of the rat brain. J. Neurochem. 45, 1021-1026. doi: 10.1111/j.1471-4159.1985.tb05517.x

Takei, N., Tsukui, H., and Hatanaka, H. (1988). Nerve growth factor increases the intracellular content of acetylcholine in cultured septal neurons from developing rats. J. Neurochem. 51, 1118-1125. doi: 10.1111/j.1471-4159.1988. tb03076.x

Teipel, S. J., Cavedo, E., Hampel, H., Grothe, M. J., Alzheimer's Disease Neuroimaging, I., and Alzheimer Precision Medicine, I. (2018). Basal forebrain volume, but not hippocampal volume, is a predictor of global cognitive decline in patients with Alzheimer's disease treated with cholinesterase inhibitors. Front. Neurol. 9:642. doi: 10.3389/fneur.2018.00642

Tomioka, T., Shimazaki, T., Yamauchi, T., Oki, T., Ohgoh, M., and Okano, H. (2014). LIM homeobox 8 (Lhx8) is a key regulator of the cholinergic neuronal function via a tropomyosin receptor kinase A (TrkA)-mediated positive feedback loop. J. Biol. Chem. 289, 1000-1010. doi: 10.1074/jbc.M113.494385

Tuszynski, M. H., Amaral, D. G., and Gage, F. H. (1990). Nerve growth factor infusion in the primate brain reduces lesion-induced cholinergic neuronal degeneration. J. Neurosci. 10, 3604-3614. doi: 10.1523/JNEUROSCI.10-1103604.1990

Tuszynski, M. H., Thal, L., Pay, M., Salmon, D. P., Bakay, R., Patel, P., et al. (2005). A phase 1 clinical trial of nerve growth factor gene therapy for Alzheimer disease. Nat. Med. 11, 551-555. doi: 10.1038/nm1239

Tuszynski, M. H., Yang, J. H., Barba, D., Hoi-Sang, U., Bakay, R. A., Pay, M. M., et al. (2015). Nerve growth factor gene therapy: activation of neuronal responses in Alzheimer disease. JAMA Neurol. 72, 1139-1147. doi: 10.1001/jamaneurol. 2015.1807

Venero, J., Knüsel, B., Beck, K., and Hefti, F. (1994). Expression of neurotrophin and trk receptor genes in adult rats with fimbria transections: effect of intraventricular nerve growth factor and brain-derived neurotrophic factor administration. Neuroscience 59, 797-815. doi: 10.1016/0306-4522(94)90 285-2

Verma, S., Kumar, A., Tripathi, T., and Kumar, A. (2018). Muscarinic and nicotinic acetylcholine receptor agonists: current scenario in Alzheimer's disease therapy. J. Pharm. Pharmacol. 70, 985-993. doi: 10.1111/jphp.12919

Whitehouse, P. J., Price, D. L., Clark, A. W., Coyle, J. T., and DeLong, M. R. (1981). Alzheimer disease: evidence for selective loss of cholinergic neurons in the nucleus basalis. Ann. Neurol. 10, 122-126. doi: 10.1002/ana.41010 0203

Whitehouse, P. J., Price, D. L., Struble, R. G., Clark, A. W., Coyle, J. T., and Delon, M. R. (1982). Alzheimer's disease and senile dementia: loss of neurons in the basal forebrain. Science 215, 1237-1239. doi: 10.1126/science.7058341

Williams, L. R., Varon, S., Peterson, G. M., Wictorin, K., Fischer, W., Bjorklund, A., et al. (1986). Continuous infusion of nerve growth factor prevents basal forebrain neuronal death after fimbria fornix transection. Proc. Natl. Acad. Sci. U.S.A. 83, 9231-9235. doi: 10.1073/pnas.83.23.9231

Conflict of Interest Statement: The authors declare that the research was conducted in the absence of any commercial or financial relationships that could be construed as a potential conflict of interest.

Copyright $\odot 2019$ Cuello, Pentz and Hall. This is an open-access article distributed under the terms of the Creative Commons Attribution License (CC BY). The use, distribution or reproduction in other forums is permitted, provided the original author(s) and the copyright owner(s) are credited and that the original publication in this journal is cited, in accordance with accepted academic practice. No use, distribution or reproduction is permitted which does not comply with these terms. 